\title{
Microvascular Hepatic Artery Reconstruction in Living Donor Liver Transplantation
}

\author{
Hideaki Uchiyama et al. ${ }^{*}$ \\ Department of Surgery and Science, Graduate School of Medical Sciences, \\ Kyushu University \\ Japan
}

\section{Introduction}

Even with the recent technical advances in the surgical procedures used for living donor liver transplantation (LDLT), hepatic artery reconstruction is still one of the most difficult procedures in LDLT (Matsuda et al., 2006; Eguchi et al., 2008). Because hepatic artery complications in liver transplantation, such as hepatic artery thrombosis (HAT) or hepatic artery dissection (HAD), often lead to devastating consequences, such as graft loss or patient death (Yanaga et al., 1990a; Settmacher et al., 2000; Stange et al., 2003), hepatic artery reconstruction should be performed using the most reliable procedure. A graft hepatic artery to be reconstructed in LDLT usually has a narrower caliber and a shorter stump compared to the arteries used during cadaveric liver transplantation. We introduced microvascular surgery for hepatic artery reconstruction in LDLT at the beginning of our LDLT program (Uchiyama et al., 2002). The use of microvascular surgery in LDLT was first reported in 1992 (Mori et al., 1992). Thereafter, many transplant centers introduced this technique for hepatic artery reconstruction in LDLT and confirmed that its application to hepatic artery reconstruction in LDLT decreased the number of hepatic artery complications (Inomoto, et al., 1996; Millis et al., 2000; Wei et al., 2004; Takatsuki et al., 2006; Panossian et al., 2009). We performed 401 cases of LDLT between October 1996 and June 2011 and almost all hepatic artery reconstructions were performed by microvascular surgery under a microscope. Microvascular surgery for hepatic artery reconstruction has been performed by general surgeons in our department. In this chapter, we present our microvascular surgical techniques used for hepatic artery reconstructions in LDLT and the outcomes of these reconstructions in 401 LDLT cases.

\section{Preoperative anatomical evaluation of graft hepatic arteries}

In our early experience, the donors underwent invasive conventional angiography to assess the anatomy of the hepatic arteries. Now, we use only CT angiography for the assessment of the donor's hepatic artery anatomy. Current CT angiography methods can be used to assess the donor's hepatic artery anatomy preoperatively with almost 100\% accuracy (Saylisoy et

\footnotetext{
* Ken Shirabe, Akinobu Taketomi, Yuji Soejima, Tomoharu Yoshizumi, Toru Ikegami, Noboru Harada, Hiroto Kayashima and Yoshihiko Maehara
} 
al., 2005; Apisarnthanarak et al., 2011). Graft hepatic arteries are usually reconstructed using the recipient hepatic arterial branches (Fig. 1).

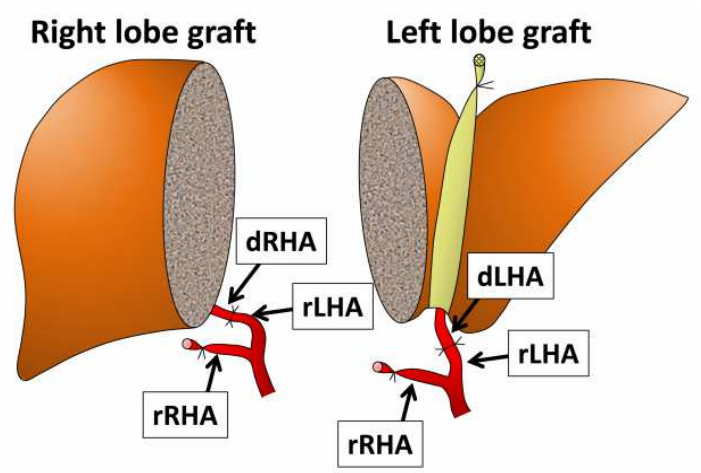

Fig. 1. A schematic diagram of hepatic artery reconstruction. dLHA, left hepatic artery of the donor; dRHA, right hepatic artery of the donor; rLHA, left hepatic artery of the recipient; rRHA, right hepatic artery of the recipient

When assessing the donor's hepatic artery anatomy, the most important consideration is to precisely predict how many hepatic arterial stumps there will be on a graft (Fig. 2). Sometimes, a hepatic graft has multiple hepatic arterial stumps, which usually have a very narrow caliber (Uchiyama et al., 2010a). Thus, LDLT using such graft makes hepatic artery reconstruction difficult. Some transplant surgeons regard such a graft as a contraindication for LDLT (Broelsch et al., 1991; Kostelic et al., 1996), and others have reported various arterial manipulations in donors that can be used to make the hepatic artery reconstruction easier (Takatsuki et al., 2006; Douard et al., 2002). On rare occasions, a hepatic graft is expected to have three or more hepatic arterial stumps by CT angiography, in which hepatic artery reconstructions are extremely difficult. In such cases, the other side graft (i.e., right lobe) or a graft from another donor may be selected.

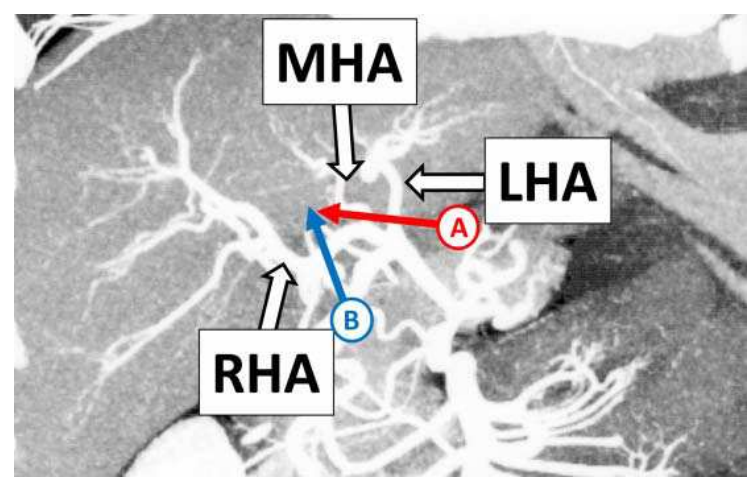

Fig. 2. The results of a CT angiographic examination of a donor. The arrow (A) indicates the dividing point of the middle and left hepatic arteries when the left lobe graft is selected, while the arrow (B) indicates the dividing point of the right hepatic artery. LHA, left hepatic artery; MHA, middle hepatic artery; RHA, right hepatic artery 


\section{Preparation of graft hepatic arteries for hepatic artery reconstruction}

The arterial flows into the donor's remnant liver should never be compromised. In procuring a graft liver, special care should be paid not to make wall dissections of graft arteries by ligating the proximal site of the hepatic artery with excessive force, because wall dissection of the arterial stump is usually irreparable. On the backtable, it is not necessary to flush the graft artery with preservation solution because the preservation time is very short in LDLT. In fact, cannulating a flushing tube into the narrow graft artery increases the risk of making a wall dissection. Furthermore, there is no need to trim the graft artery on the backtable.

After the portal vein is reperfused and hemostasis is obtained to a certain degree, microvascular hepatic artery reconstruction is started. The micro-instruments and the microscope we usually use are shown in Figs. 3 and 4, respectively. Microvascular hepatic artery reconstruction is performed by 3 surgeons (Fig. 5). The primary surgeon and the first assistant face each other looking into the lens of the microscope. The second assistant exposes the surgical field.

First, the hepatic graft is brought up or rotated in a proper position to fully visualize the graft hepatic arteries (Fig. 6). The graft hepatic arteries in a right lobe graft usually exist deep in the right subdiaphragmatic space. By putting several piles of folded gauze under the graft liver, the graft artery is brought up, which makes the hepatic artery reconstruction easier. The graft hepatic arteries in a left lobe graft are usually covered by the graft itself. By pulling the round ligament upward or using a brain retractor, the graft hepatic artery can be exposed. It is very difficult to expose the graft hepatic arteries on a lateral graft used for small infants because of the very small abdominal cavity relative to the hepatic graft. However, by rotating the graft liver clockwise and pushing it into the left subdiaphragmatic space made by pulling down the spleen, the graft hepatic artery can be exposed.

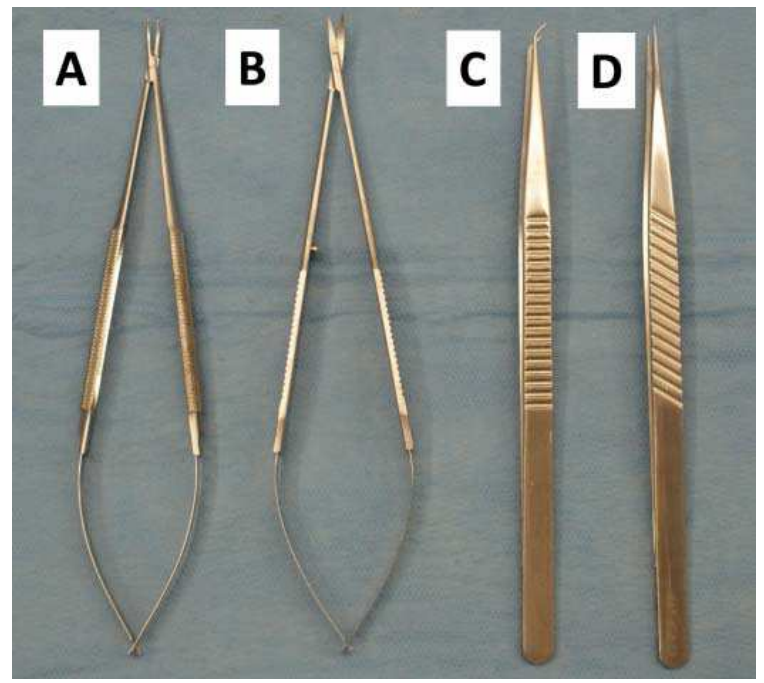

Fig. 3. Instruments used for microvascular hepatic artery reconstruction (A) Needle holder (Aesculap, FD245R). (B) Micro scissors (Aesculap, FD023R). (C) Angulated micro forceps (S \& T, JFAL-3-18). (D) Straight micro forceps (S \& T, JF-3-18) 


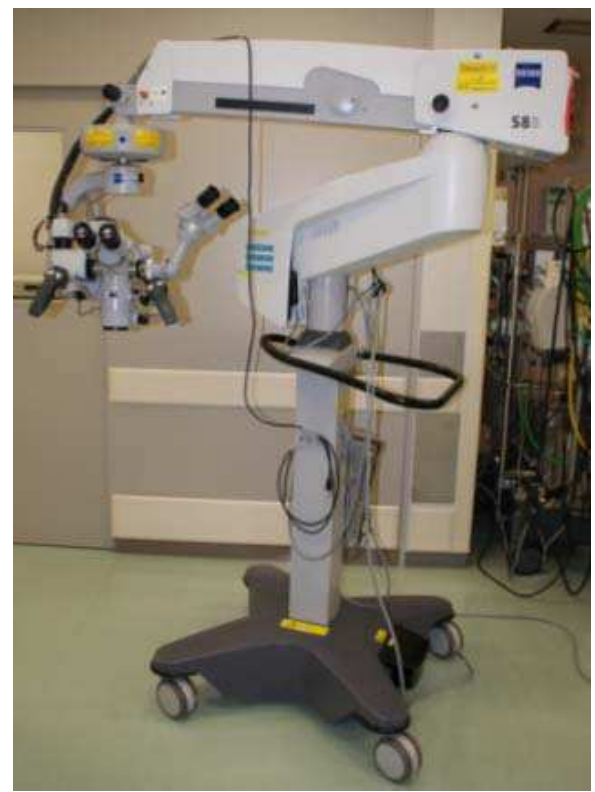

Fig. 4. The surgical microscope used for microvascular hepatic artery reconstruction (Carl Zeiss, OPMI VARIO S88). This microscope has a foot pedal. The surgeon can adjust the microscope using this foot pedal without interrupting the procedure

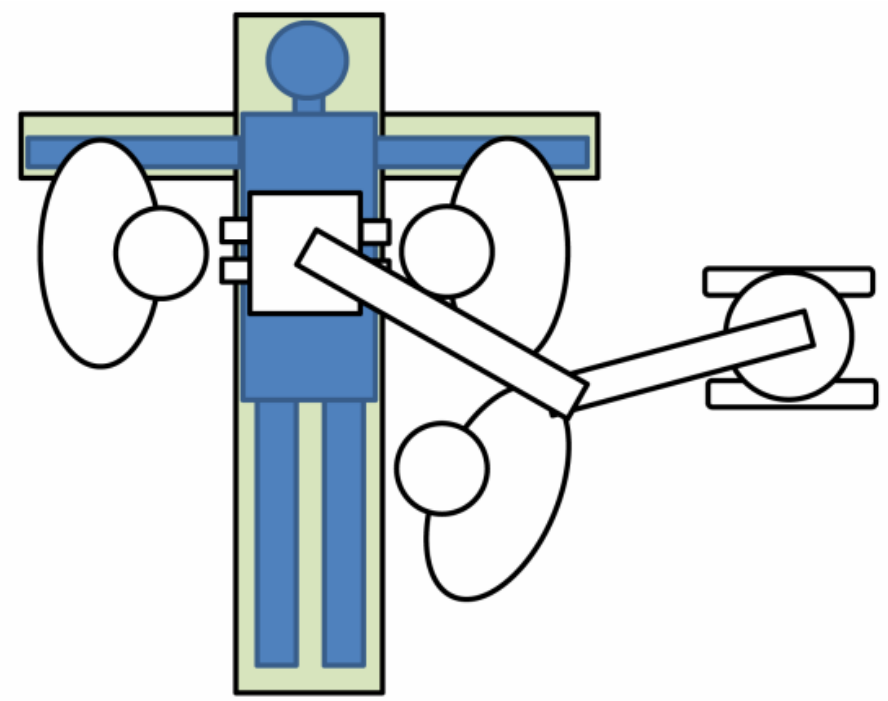

Fig. 5. The positioning of the microvascular surgeons. The primary surgeon stands on the right side of the recipient. The first assistant stands on the left side of a recipient, looking into the other lens of a microscope. The second assistant stands next to the first assistant and exposes the surgical field 

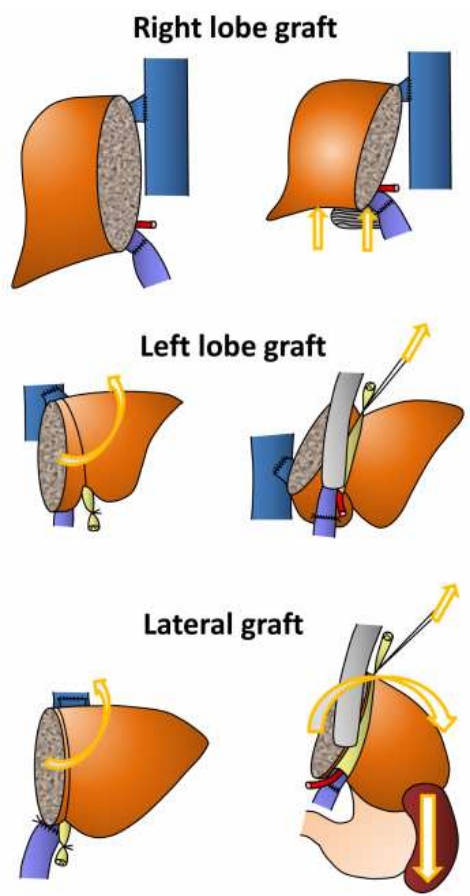

Fig. 6. The positioning of the hepatic grafts required to visualize the graft hepatic artery. Hepatic grafts are positioned in order to fully expose the graft arteries

In preparing the graft hepatic arteries for anastomosis, they should be gently manipulated so as not to injure the arterial wall (Fig. 7). When a surgeon wants to move the arterial stump, only the surrounding connective tissue should be grasped.

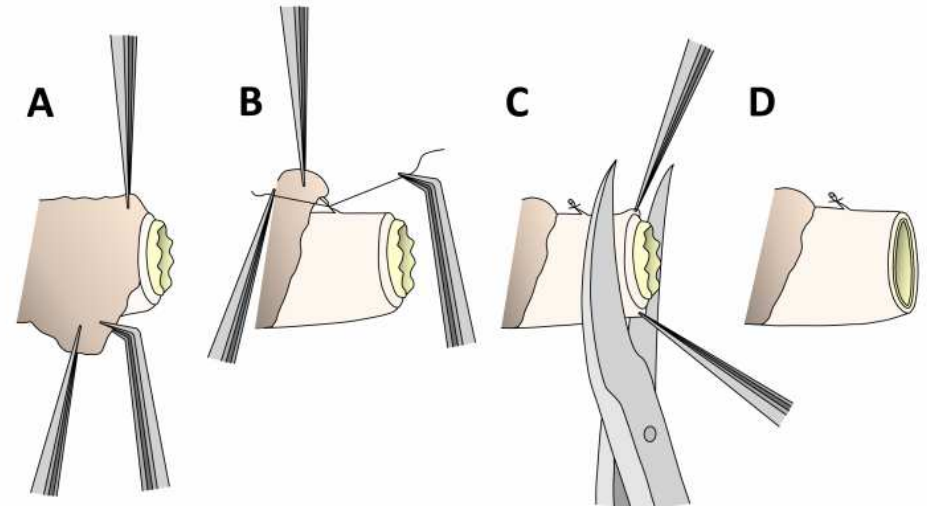

Fig. 7. Preparation of the graft hepatic artery. (A) The outer surrounding connective tissue is removed from the artery. (B) Sometimes, small branches are encountered. These are ligated with 8-0 Prolene ${ }^{\mathrm{TM}}$ string and cut. (C) The edge of the arterial stump is trimmed off. (D) Then, the graft hepatic artery is ready to be anastomosed 


\section{Preparation of recipient hepatic arteries for hepatic artery reconstruction}

The recipient arteries to be used for hepatic artery reconstruction are usually hepatic arterial branches, such as the left hepatic artery, the middle hepatic artery, and the right hepatic artery. First, we determine how many graft hepatic arteries should be reconstructed. In our experience, $28 \%$ of hepatic grafts have two or more graft hepatic arteries (Table 1 ).

Most of them are left hepatic grafts. Despite the greater difficulty of hepatic artery reconstruction when selecting left hepatic grafts with multiple hepatic arteries, we prefer to use a left hepatic graft because it increases donor's safety (Nishizaki et al., 2001; Soejima et al., 2006; Taketomi et al., 2009).

\begin{tabular}{|c|c|c|c|}
\hline $\begin{array}{l}\text { Graft type } \\
\text { No. of arterial stumps }\end{array}$ & $\mathbf{N}$ & $\begin{array}{l}\text { No. of reconstructed } \\
\text { arteries }\end{array}$ & $\begin{array}{l}\text { N (total number of } \\
\text { reconstructed arteries) }\end{array}$ \\
\hline Left lateral & 33 & & \\
\hline One stump & 27 & One reconstruction & $27(27)$ \\
\hline \multirow[t]{2}{*}{ Two stumps } & 6 & One reconstruction & $3(3)$ \\
\hline & & Two reconstructions & $3(6)$ \\
\hline Left & 240 & & \\
\hline \multirow[t]{2}{*}{ One stump } & 146 & No reconstruction & $1(0)$ \\
\hline & & One reconstruction & $145(145)$ \\
\hline \multirow[t]{2}{*}{ Two stumps } & 88 & One reconstruction & $30(30)$ \\
\hline & & Two reconstructions & $58(116)$ \\
\hline \multirow[t]{3}{*}{ Three strumps } & 6 & One reconstruction & $1(1)$ \\
\hline & & Two reconstructions & $2(4)$ \\
\hline & & Three reconstructions & $3(9)$ \\
\hline Right & 124 & & \\
\hline One stump & 117 & One reconstruction & $117(117)$ \\
\hline \multirow[t]{2}{*}{ Two stumps } & 7 & One reconstruction & $0(0)$ \\
\hline & & Two reconstructions & $7(14)$ \\
\hline Posterior & 5 & & \\
\hline One stump & 5 & One reconstruction & $5(5)$ \\
\hline Total & 402 & & (477) \\
\hline
\end{tabular}

Table 1. A summary of hepatic artery reconstruction. Note: Because one recipient received dual grafts, the total number of hepatic grafts is 402 in 401 LDLTs 
Most of the reported donor deaths are the result of right hepatic lobe donation (Miller et al., 2004; Akabayashi et al., 2004; Trotter et al., 2006; Ghobrial et al., 2008). Although some surgeons have stated that it is not always necessary for all graft hepatic arteries to be reconstructed when backflows are observed from the second graft hepatic artery after reconstruction of the first artery (Ikegami et al., 1996; Kubota et al., 2000) because of the collateral arterial blood supply of the liver (Plengvanit et al., 1972), our policy for a graft with two or more graft hepatic arteries is that all graft hepatic arteries should be reconstructed if it is technically feasible (Uchiyama, 2010a). Incomplete hepatic artery reconstruction may result in relative arterial ischemia in a hepatic graft, which leads to biliary stricture, abscess formation, and so on (Yanaga, et al. 1990b; Suehiro, et al. 2002).

To increase the number of candidate recipient hepatic arteries and in cases of very short graft hepatic arteries, the recipient hepatic arterial branches must be divided as peripherally as possible. When dividing hepatic arterial branches, a surgeon should pay special attention not to make a wall dissection. Patients with end-stage liver disease have enlarged hepatic arteries to compensate for their decreased portal venous flow, and as a result, they tend to have fragile hepatic arterial walls. Once an arterial wall dissection occurs, it often extends to the proximal celiac trunk and none of the tributary arteries of the celiac trunk can then be used for hepatic artery reconstruction. To avoid this devastating complication, we first gently tie a hepatic artery, then we place the second knot with a relatively secure force just above the first knot. The artery is then divided just above the second knot.

In selecting which hepatic arterial branch to use as an inflow artery, we prefer to use the left hepatic artery (Uchiyama et al., 2010b). Patients with end-stage liver disease usually have a relatively large left hepatic arteries, of the proper size for hepatic artery reconstruction, because of the compensation for the decreased portal venous flow. Furthermore, our first choice for biliary reconstruction is currently duct-to-duct biliary reconstruction, which makes hepatic artery reconstructions using the recipient right hepatic artery relatively difficult. The recipient bile duct is partly nourished by small branches of the right hepatic artery. To make the right hepatic artery easy to use for reconstruction, the connective tissues between the common hepatic duct and the right hepatic artery are somewhat divided, which may disrupt those small nourishing arteries flowing into the common hepatic duct (Chen et al., 1999; Gunji et al., 2006). The ischemia of the bile duct is considered to be one of the leading causes of anastomotic biliary stricture (Fan et al., 2002). On the other hand, if the connective tissue is untouched for fear of disrupting the nourishing arteries, not only is it more difficult to reconstruct the hepatic artery using the right hepatic artery because the right hepatic artery does not have good flexibility, but also there will be a kink at the anastomosis site after performing duct-to-duct anastomosis.

When the recipient hepatic arterial branches cannot be used for an inflow artery, as in the case of a stiff arterial wall caused by repeated transarterial chemoembolization for hepatocellular carcinoma (Lin et al., 2009), or intraoperative arterial injury, a surgeon should use any recipient arteries other than hepatic arterial branches, such as the gastric arteries (Wang et al., 2008; Ikegami et al., 2000), as an inflow artery because a hepatic graft without any arterial flow may often succumb to graft failure or sepsis. We call this mode of hepatic artery reconstruction extra-anatomical hepatic artery reconstruction (Uchiyama et al., 2010c). In reconstructing graft hepatic arteries extra-anatomically, we use the right gastroepiploic artery, the right gastric artery, the gastroduodenal artery, and so on (Table 2). 


\begin{tabular}{|c|c|}
\hline Inflow artery & $\mathbf{N}$ \\
\hline Anatomical inflow & 445 \\
\hline Left hepatic artery & 245 \\
\hline Right hepatic artery & 107 \\
\hline Middle hepatic artery & 53 \\
\hline Anterior branch of the right hepatic artery & 11 \\
\hline Posterior branch of the right hepatic artery & 9 \\
\hline Replaced left hepatic artery & 8 \\
\hline Proper hepatic artery & 6 \\
\hline Common hepatic artery & 3 \\
\hline Replaced right hepatic artery & 1 \\
\hline A2 artery & 1 \\
\hline A3 artery & 1 \\
\hline Extra-anatomical inflow & 32 \\
\hline Right gastroepiploic artery & 12 \\
\hline Right gastric artery & 7 \\
\hline Gastroduodenal artery & 7 \\
\hline Cystic artery & 3 \\
\hline Splenic artery & 2 \\
\hline Left gastric artery & 1 \\
\hline Total & 477 \\
\hline
\end{tabular}

Table 2. A summary of the recipient inflow arteries used in hepatic artery reconstructions

So far, we have used only 3 interposition vessel grafts for hepatic artery reconstruction, namely one right gastric vein graft (Uchiyama et al., 2007), one splenic artery graft and one superior rectal artery graft. The right gastric vein graft was used to fill a gap between the graft artery and the recipient inflow artery. The Y-shaped splenic artery graft was used to reconstruct two graft arteries from one inflow artery. The superior rectal artery graft was used to taper the caliber of a large recipient inflow artery. Because the use of an interposition graft necessitates at least two anastomoses, which may increase the rate of hepatic artery complications, it should be considered a last resort for hepatic artery reconstruction.

In preparing the recipient arteries, the outer surrounding tissue around the recipient candidate hepatic arteries has to be meticulously removed (Fig. 8).

Recipients with end-stage liver disease often have dense nerve fibers and lymphatic vessels around the hepatic arteries. These fibers and vessels are obstacles for hepatic artery 
reconstruction and should be removed. Adequate blood flow is confirmed by releasing the proximal forceps.
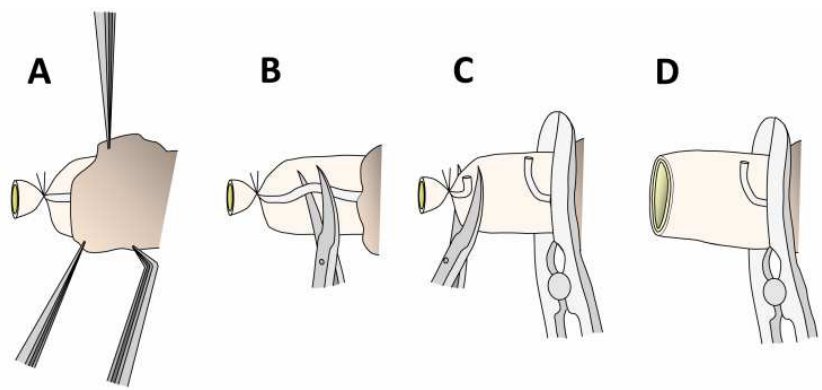

Fig. 8. Preparation of the recipient hepatic artery. (A) The outer surrounding tissue is removed from the recipient hepatic artery. (B) Sometimes, nerve fibers are firmly attached to the artery. These are dissected from the artery and divided. (C) After the proximal portion of the artery is clamped, the distal end of the artery is cut open. (D) The intact arterial flow is confirmed by temporary declamping of the artery, and the recipient artery is ready to be anastomosed
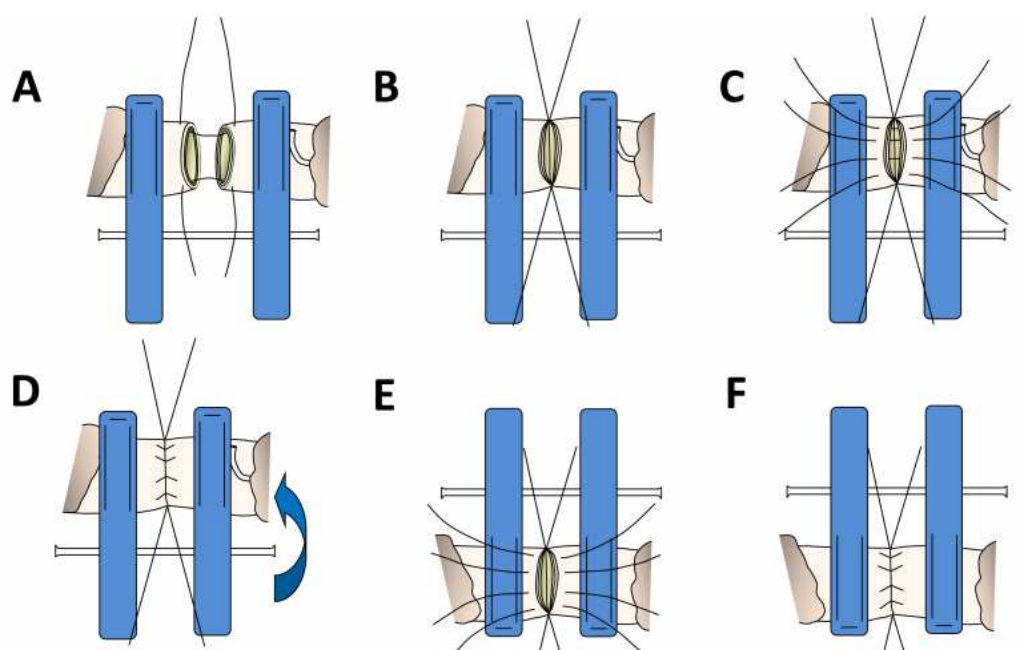

$\mathbf{E}$

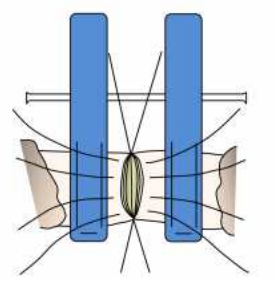

$\mathbf{F}$

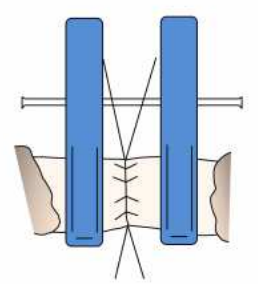

Fig. 9. Hepatic artery reconstruction using a double-clip. (A) After removal of the outer connective tissue surrounding both the donor and recipient arteries, these are secured by a double-clip. Angle stitches (8-0 or 9-0 non-absorbable sutures) are placed on both edges of the arteries. (B) After the clips are moved inward so that both arteries are attached to each other, the angle stitches are tied. (C) Several stitches (usually 4 or 5 stitches) are placed between the angle stitches. The number of stitches is determined according to the diameter of the arteries. These stitches are left untied until all stitches are placed, because it is easier to place each stitch correctly before they are tied, which is called the untied suture technique (Harashina, 1977). (D) These stitches are tied one-by-one. Then, the double-clip is turned over. (E, F) Several stitches are placed on the other side of the arteries in the same manner 


\section{Hepatic artery anastomosis}

After the preparation of both the donor and recipient hepatic arteries is complete, then the final step is to actually reconstruct the graft hepatic arteries. When considering the hemodynamics of the arterial flow, a direct end-to-end anastomosis is the preferred mode of reconstruction. All hepatic artery reconstructions we experienced were done by a direct endto-end anastomosis. A size-discrepancy up to 2 times is usually acceptable. However, anastomosing so large a recipient artery to a thin graft artery may lead to a rupture of the anastomosis. In such cases, another recipient artery should be selected. So far, we have never experienced a case that required end-to-side anastomosis.

\subsection{Hepatic artery anastomosis using a double-clip}

We prefer to use a disposable double-clip for performing anastomosis (Fig. 9). The desired grasp force is 45 to 60 grams. By fixing both the graft and recipient arteries, excessive forces at the anastomosis can be avoided.
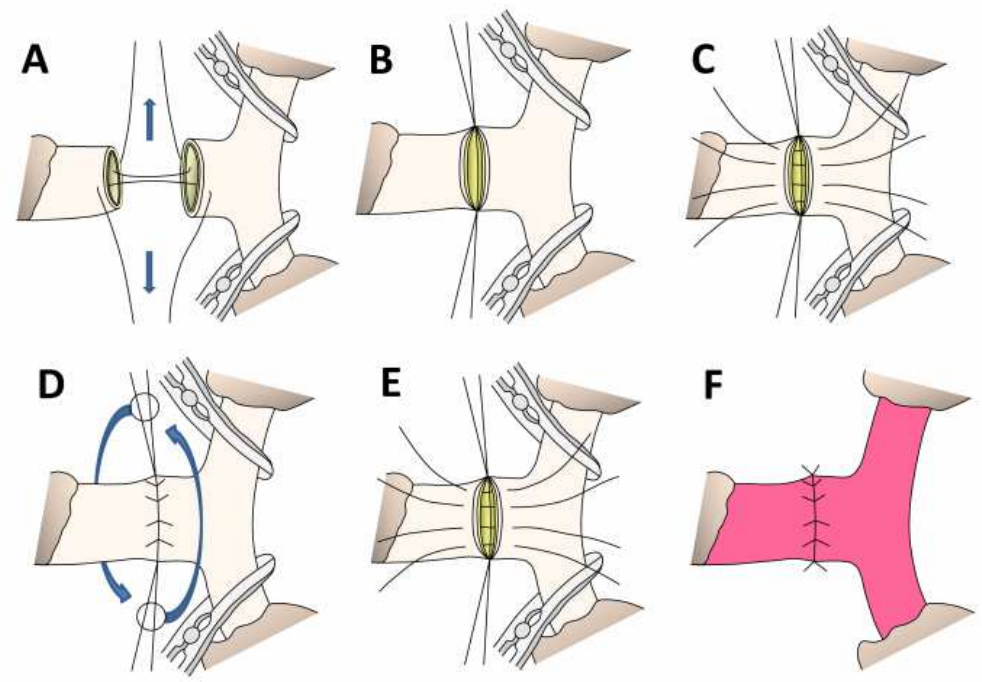

Fig. 10. Hepatic artery reconstruction without a double-clip. (A) After removal of the outer connective tissue surrounding both the donor and recipient arteries, angle stitches are placed on the 6 o'clock and the 12 o'clock positions. (B) After the angle stitches are tied, these stitches are pulled in opposite directions using light clamps so that the arterial walls between the angle stitches are held horizontal with appropriate tension. (C) Several stitches (usually 4 or 5 stitches) are placed between the angle stitches. The number of stitches is determined according to the diameter of the arteries. These stitches are left untied until all stitches are placed, because it is easier to place each stitch correctly before they are tied, which is called the untied suture technique (Harashina, 1977). (D) These stitches are tied one-by-one. The arteries being anastomosed are turned over by pulling each angle stitch in the opposite direction. (E, F) Several stitches are placed on the other side of the arteries in the same manner 


\subsection{Hepatic artery anastomosis without a double-clip}

Sometimes, surgeons encounter a situation where a double-clip cannot grasp the arteries to be anastomosed because of the stiffness of the arteries or because the stump is too short. In such situations, hepatic arteries are reconstructed using two tension stitches placed at the 6 o'clock and 12 o'clock positions (Fig. 10).

\section{Posttransplant management}

Daily Doppler ultrasound should be performed to check for intact hepatic arterial flows for 7 days after transplantation (Fig. 11). We use neither anti-coagulant nor anti-platelet agents for the purpose of preventing hepatic artery thrombosis. Current Doppler ultrasound machines are so accurate (Kaneko et al., 2004) that they rarely give false positive results (good pulsatile hepatic arterial flows in the graft are detected even when there is a hepatic arterial problem). Whenever there is no pulsatile hepatic arterial flow on Doppler ultrasonography, the patient should immediately undergo contrast-enhanced CT. If there is a suspicion of hepatic artery complications, invasive angiography should be performed, and any attempts to restore the hepatic arterial flow into the graft need to be made within several hours, or devastating consequences (graft failure, sepsis, etc.) will occur.

With regard to repairing hepatic artery complications, our first choice is surgical revision of the HA anastomosis, although there have been some reports regarding non-surgical interventional therapy or retransplantation (Maleux et al., 2005; Kodama et al., 2006; Fistouris et al., 2006).

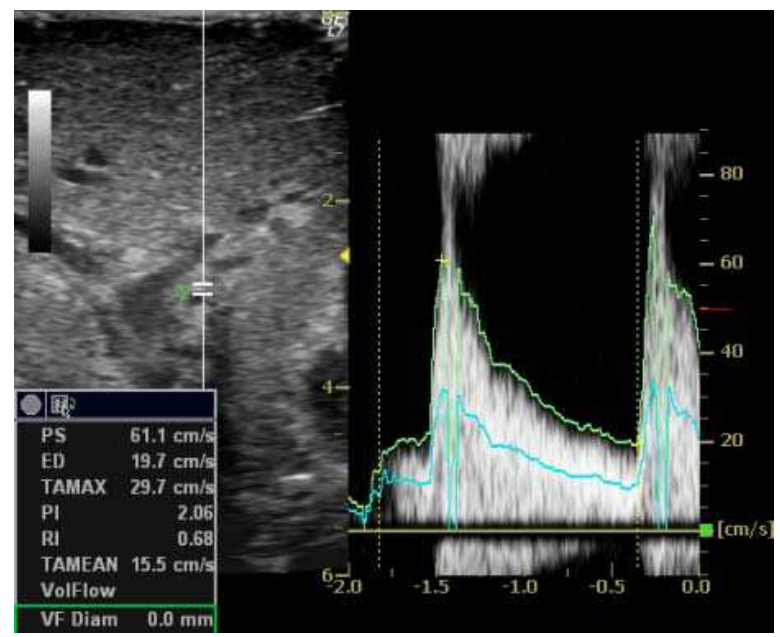

Fig. 11. Doppler ultrasonography is used to detect the intact hepatic arterial flow in the graft liver

\section{Hepatic artery complications after living donor liver transplantation}

So far, we have experienced 6 hepatic artery complications (Table 3, Fig. 12). Most of them occurred in our early experience. 
Patient \#17 underwent an auxiliary partial orthotopic LDLT. The case was previously reported as a case report (Uchiyama et al., 2007). The left hepatic graft had a single left hepatic artery, which was reconstructed using the right gastric artery interposed by the right gastric vein graft. There was a restriction on the use of recipient inflow arteries because the native residual liver also had to receive arterial inflows. The patient underwent a follow-up CT examination at 4 years after the LDLT without any symptoms, and an aneurysm at the vein graft was found incidentally. Six months later, the patient underwent a follow-up CT examination again, and the aneurysm was found to be growing. We performed an aneurysm resection and hepatic artery re-reconstruction using the right gastroepiploic artery. The patient is now alive and still doing well at 12 years and 3 months posttransplant.

Patient \#18 suffered refractory anastomotic bile leakage after the first LDLT and had to undergo repeated drainage tube insertions to drain infected biloma. On posttransplant day 28, the serous transaminases were steeply elevated and the pulsatile hepatic arterial flows disappeared on Doppler ultrasonography. Emergency angiography was performed which revealed that there was no hepatic artery inflow into the hepatic graft. Although we tried to re-reconstruct the hepatic artery, the tissues around the hepatic hilum had become very fragile because of the infected biloma and we could not perform hepatic artery rereconstruction. The patient underwent re-LDLT and is still alive at 12 years and 2 months posttransplant.

Patient \#39 experienced an unstable clinical course after LDLT, in which hypotension, atrial fibrillation, and oliguria persisted. On posttransplant day 7 , the serum transaminases were steeply elevated and no pulsatile arterial flows in the hepatic graft could be detected. Emergency angiography revealed that there was a hepatic artery thrombosis at the anastomosis. An emergency operation was performed to restore the hepatic arterial flows into the graft. The thrombus partially extended into the graft from the origin at the anastomosis. After the thrombus was removed from the graft hepatic artery as much as possible, the arterial re-reconstruction was accomplished using the recipient gastroduodenal artery. Nevertheless, the patient died of multiple organ failure with intact hepatic arterial flows on postransplant day 10.

Patient \#73 received a right hepatic graft and the right hepatic artery was anastomosed to the right hepatic artery of the recipient. On posttransplant day 7, the pulsatile flows on Doppler ultrasonography were shown to be weakened, and emergency angiography revealed there was an arterial wall dissection which extended $3 \mathrm{~cm}$ proximally from the anastomosis. The dissected wall was resected, and the graft hepatic artery was rereconstructed using the left gastric artery.

Patient \#203 received a right hepatic graft with two hepatic arterial stumps. The main right hepatic artery and the accessory A6 artery were each reconstructed using the anterior branch of the right hepatic artery and the posterior branch of the posterior branch of the right hepatic artery, respectively. This was an ABO-incompatible case, and a cannulation tube was inserted into the hepatic artery for local graft infusion therapy (Egawa et al., 2008), which was considered to have caused the later hepatic artery complication. On the posttransplant day 10, the pulsatile flows on Doppler ultrasonography were shown to be weakened, and emergency angiography revealed there was an arterial wall dissection which extended proximally from the anastomosis with intact A6 arterial flow. We considered that 


\begin{tabular}{|c|c|c|c|c|}
\hline LDLT No. & Complication & Presentation & Treatment & Outcome \\
\hline$\# 17$ & $\begin{array}{l}\text { Hepatic artery } \\
\text { aneurysm }\end{array}$ & $\begin{array}{l}\text { Incidental finding } \\
\text { on a follow-up CT }\end{array}$ & $\begin{array}{l}\text { Aneurysmal resection and hepatic artery } \\
\text { re-reconstruction }\end{array}$ & $\begin{array}{l}12 \mathrm{y} \text { and } 3 \mathrm{~m} \\
\text { posttransplant, alive }\end{array}$ \\
\hline$\# 18$ & $\begin{array}{l}\text { Hepatic artery } \\
\text { thrombosis }\end{array}$ & $\begin{array}{l}\text { Elevation of } \\
\text { transaminases }\end{array}$ & $\begin{array}{l}\text { Unable to re-reconstruct the hepatic } \\
\text { artery. Living donor re-transplantation } \\
\text { was performed. }\end{array}$ & $\begin{array}{l}12 \mathrm{y} \text { and } 2 \mathrm{~m} \\
\text { posttransplant, alive }\end{array}$ \\
\hline$\# 39$ & $\begin{array}{l}\text { Hepatic artery } \\
\text { thrombosis }\end{array}$ & $\begin{array}{l}\text { Elevation of } \\
\text { transaminases }\end{array}$ & Hepatic artery re-reconstruction & $\begin{array}{l}10 \text { days posttransplant, } \\
\text { died of multiple organ } \\
\text { failure }\end{array}$ \\
\hline$\# 73$ & $\begin{array}{l}\text { Hepatic artery } \\
\text { dissection }\end{array}$ & $\begin{array}{l}\text { Dullness of hepaic } \\
\text { arterial flow on } \\
\text { Doppler } \\
\text { ultrasonography }\end{array}$ & Hepatic artery re-reconstruction & $\begin{array}{l}11 \mathrm{y} \text { and } 5 \mathrm{~m} \\
\text { posttransplant, alive }\end{array}$ \\
\hline$\# 203$ & $\begin{array}{l}\text { Hepatic artery } \\
\text { dissection }\end{array}$ & $\begin{array}{l}\text { Dullness of hepaic } \\
\text { arterial flow on } \\
\text { Doppler } \\
\text { ultrasonography }\end{array}$ & Hepatic artery re-reconstruction & $\begin{array}{l}5 \mathrm{y} \text { and } 8 \mathrm{~m} \\
\text { posttransplant, alive }\end{array}$ \\
\hline$\# 292$ & $\begin{array}{l}\text { Hepatic artery } \\
\text { aneurysm }\end{array}$ & $\begin{array}{l}\text { Incidental finding } \\
\text { on a follow-up CT }\end{array}$ & Hepatic artery re-reconstruction & $\begin{array}{l}2 \mathrm{y} \text { and } 10 \mathrm{~m} \\
\text { posttransplant, alive }\end{array}$ \\
\hline
\end{tabular}

Table 3. The hepatic artery complications in our series

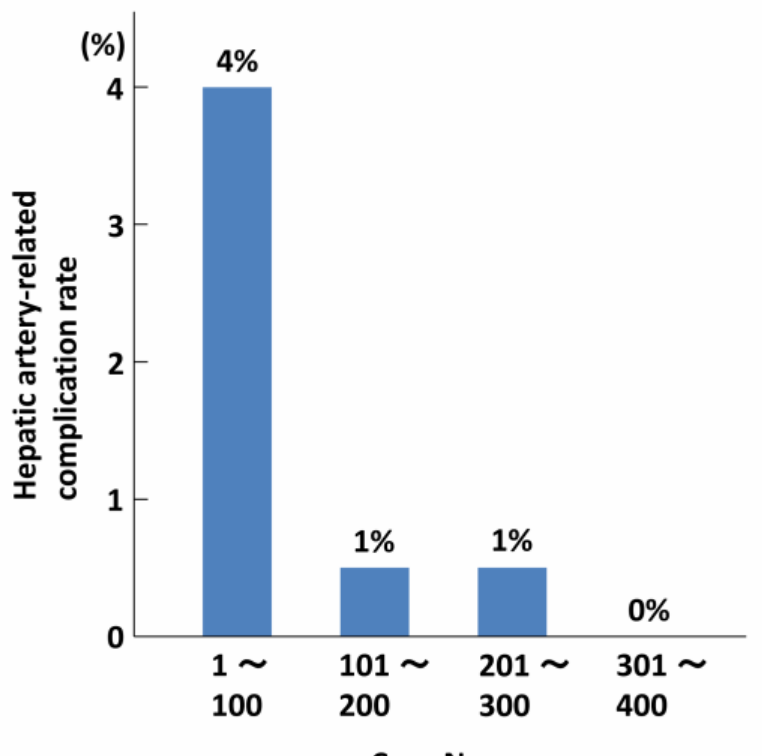

Case No.

Fig. 12. The hepatic artery-related complication rate in our series 
this tiny A6 artery could not sustain the right hepatic graft, and a reoperation was performed. The dissected wall was resected, and the graft main right hepatic artery was rereconstructed using the recipient right gastroepiploic artery.

Patient \#292 received a left lobe graft with two graft hepatic arteries. The graft replaced left hepatic artery and the graft middle hepatic artery were anastomosed to the recipient left hepatic artery and the recipient middle hepatic artery, respectively. The patient was incidentally found to have an aneurysm at the anastomosis between the graft replaced left hepatic artery and the recipient left hepatic artery. The aneurysm was resected and the graft replaced left hepatic artery was re-reconstructed.

\section{Conclusion}

With the technical advances made in hepatic artery reconstruction, plus our experience with the procedures, we have not recently encountered any hepatic artery-related complications. Although mastering microvascular surgical techniques is time-consuming, we think that this is the most reliable procedure for hepatic artery reconstruction, especially in LDLT for small recipients. The next issue that must be addressed is how to securely pass these techniques to the next generation.

\section{References}

Akabayashi, A., Slingsby, B.T. \& Fujita, M. (2004) The first donor death after living-related liver transplantation in Japan. Transplantation Vol. 77(No. 4): 634.

Apisarnthanarak, P., Raman, S.S., Ghobrial, R.M., Busuttil, R.W., Saab, S. \& Lu, D.S. (2011) Efficacy of CT angiography for preoperative vascular mapping in adult to adult living related liver transplant donors. J Med Assoc Thai Vol. 94(No. 1): 98105.

Broelsch, C.E., Whitington, P.F., Emond, J.C., Heffron, T.G., Thistlethwaite, J.R., Stevens, L., Piper, J., Whitington, S.H. \& Lichtor, J.L. (1991) Liver transplantation in children from living related donors. Surgical techniques and results. Ann Surg Vol. 214(No. 4): 428-437.

Chen, W.J., Ying, D.J., Liu, Z.J. \& He, Z.P. (1999) Analysis of the arterial supply of the extrahepatic bile ducts and its clinical significance. Clin Anat Vol. 12(No. 4): 245249.

Douard, R., Ettorre, G.M., Sommacale, D., Jan, D., Révillon, Y., Farges, O. \& Belghiti, J. (2002) A two-step strategy for enlargement of left arterial branch in a living related liver graft with dual arterial supply. Transplantation Vol. 73(No. 6): 993-994.

Egawa, H., Teramukai, S., Haga, H., Tanabe, M., Fukushima, M. \& Shimazu, M. (2008) Present status of ABO-incompatible living donor liver transplantation in Japan. Hepatology Vol. 47(No. 1): 143-152.

Eguchi, S., Takatsuki, M., Hidaka, M., Tajima, Y. \& Kanematsu, T. (2008) Evolution of living donor liver transplantation over 10 years: experience of a single center. Surg Today Vol. 38(No. 9): 795-800. 
Fan, S.T., Lo, C.M., Liu, C.L., Tso, W.K. \& Wong, J. (2002) Biliary reconstruction and complications of right lobe live donor liver transplantation. Ann Surg Vol. 236(No. 5): 676-683.

Fistouris, J., Herlenius, G., Bäckman, L., Olausson, M., Rizell, M., Mjörnstedt, L. \& Friman, S. (2006) Pseudoaneurysm of the hepatic artery following liver transplantation. Transplant Proc Vol. 38(No. 8): 2679-2682.

Ghobrial, R.M., Freise, C.E., Trotter, J.F., Tong, L., Ojo, A.O., Fair, J.H., Fisher, R.A., Emond, J.C., Koffron, A.J., Pruett, T.L., Olthoff, K.M. \& A2ALL Study Group. (2008) Donor morbidity after living donation for liver transplantation. Gastroenterology Vol. 135(No.2): 468-476.

Gunji, H., Cho, A., Tohma, T., Okazumi, S., Makino, H., Shuto, K., Mochizuki, R., Matsubara, K., Hayano, K., Mori, C., Murakami, G. \& Ochiai, T. (2006) The blood supply of the hilar bile duct and its relationship to the communicating arcade located between the right and left hepatic arteries. Am J Surg Vol. 192(No. 3): 276280.

Harashina, T. (1977) Use of the untied suture in microvascular anastomoses. Plast Reconstr Surg Vol. 59(No. 1): 134-135.

Ikegami, T., Kawasaki, S., Hashikura, Y., Miwa, S., Kubota, T., Mita, A., Iijima, S., Terada, M., Miyagawa, S. \& Furuta, S. (2000) An alternative method of arterial reconstruction after hepatic arterial thrombosis following living-related liver transplantation. Transplantation Vol. 69(No. 9): 1953-1955.

Ikegami, T., Kawasaki, S., Matsunami, H., Hashikura, Y., Nakazawa, Y., Miyagawa, S., Furuta, S., Iwanaka, T. \& Makuuchi, M. (1996) Should all hepatic arterial branches be reconstructed in living-related liver transplantation? Surgery Vol. 119(No. 4): 431-436.

Inomoto, T., Nishizawa, F., Sasaki, H., Terajima, H., Shirakata, Y., Miyamoto, S., Nagata, I., Fujimoto, M., Moriyasu, F., Tanaka, K. \& Yamaoka, Y. (1996) Experience of 120 microsurgical reconstructions of hepatic artery in living related liver transplantation. Surgery Vol. 119(No. 1): 20-26.

Kaneko, J., Sugawara, Y., Akamatsu, N., Kishi, Y., Niiya, T., Kokudo, N., Makuuchi, M. \& Mizuta, K. (2004) Prediction of hepatic artery thrombosis by protocol Doppler ultrasonography in pediatric living donor liver transplantation. Abdom Imaging Vol. 29 (No. 5): 603-605.

Kodama, Y., Sakuhara, Y., Abo, D., Shimamura, T., Furukawa, H., Todo, S. \& Miyasaka, K. (2006) Percutaneous transluminal angioplasty for hepatic artery stenosis after living donor liver transplantation. Liver Transpl Vol. 12 (No. 3): 465-469.

Kostelic, J.K., Piper, J.B., Leef, J.A., Lu, C.T., Rosenblum, J.D., Hackworth, C., Kahn, J., Thistlethwaite, J.R. \& Whitington, P.F. (1996) Angiographic selection criteria for living related liver transplant donors. AJR Am J Roentgenol Vol. 166(No. 5): 11031108.

Kubota, K., Makuuchi, M., Takayama, T., Harihara, Y., Hasegawa, K., Aoki, T., Asato, H. \& Kawarasaki, H. (2000) Simple test on the back table for justifying single hepaticarterial reconstruction in living related liver transplantation. Transplantation Vol. 70(No. 4): 696-697. 
Lin, T.S., Chiang, Y.C., Chen, C.L., Concejero, A.M., Cheng, Y.F., Wang, C.C., Wang, S.H., Liu, Y.W., Yang, C.H. \& Yong, C.C. (2009) Intimal dissection of the hepatic artery following transarterial embolization for hepatocellular carcinoma: an intraoperative problem in adult living donor liver transplantation. Liver Transpl Vol. 15(No. 11): 1553-1556.

Maleux, G., Pirenne, J., Aerts, R. \& Nevens, F. (2005) Case report: hepatic artery pseudoaneurysm after liver transplantation: definitive treatment with a stent-graft after failed coil embolisation. Br J Radiol Vol. 78(No. 929): 453-456.

Matsuda, H., Yagi, T., Sadamori, H., Matsukawa, H., Shinoura, S., Murata, H., Umeda, Y. \& Tanaka, N. (2006) Complications of arterial reconstruction in living donor liver transplantation: a single center experience. Surg Today Vol. 36(No. 3): 245-251.

Miller, C., Florman, S., Kim-Schluger, L., Lento, P., De La Garza, J., Wu, J., Xie, B., Zhang, W., Bottone, E., Zhang, D. \& Schwartz, M. (2004) Fulminant and fatal gas gangrene of the stomach in a healthy live liver donor. Liver Transpl Vol. 10(No. 10): 13151319.

Millis, J.M., Cronin, D.C., Brady, L.M., Newell, K.A., Woodle, E.S., Bruce, D.S., Thistlethwaite, J.R. \& Broelsch, C.E. (2000) Primary living-donor liver transplantation at the University of Chicago: technical aspects of the first 104 recipients. Ann Surg Vol. 232(No. 1): 104-111.

Mori, K., Nagata, I., Yamagata, S., Sasaki, H., Nishizawa, F., Takada, Y., Moriyasu, F., Tanaka, K., Yamaoka, Y., Kumada, K., et al. (1992) The introduction of microvascular surgery to hepatic artery reconstruction in living-donor liver transplantation - its surgical advantages compared with conventional procedures. Transplantation Vol. 54(No. 2): 263-268.

Nishizaki, T., Ikegami, T., Hiroshige, S., Hashimoto, K., Uchiyama, H., Yoshizumi, T., Kishikawa, K., Shimada, M. \& Sugimachi, K. (2001) Small graft for living donor liver transplantation. Ann Surg Vol. 233(No. 4): 575-580.

Panossian, A., Diamond, I., Fecteau, A., Grant, D. \& Zuker, R. (2009) Hepatic artery microvascular anastomosis in pediatric living donor liver transplantation: a review of 35 consecutive cases by a single microvascular surgeon. J Reconstr Microsurg Vol. 25(No. 7): 439-443.

Plengvanit, U., Chearanai, O., Sindhvananda, K., Dambrongsak, D., Tuchinda, S. \& Viranuvatti, V. (1972) Collateral arterial blood supply of the liver after hepatic artery ligation, angiographic study of twenty patients. Ann Surg Vol. 175(No. 1): 105-110.

Saylisoy, S., Atasoy, C., Ersöz, S., Karayalçin, K. \& Akyar, S. (2005) Multislice CT angiography in the evaluation of hepatic vascular anatomy in potential right lobe donors. Diagn Interv Radiol Vol. 11(No. 1): 51-59.

Settmacher, U., Stange, B., Haase, R., Heise, M., Steinmüller, T., Bechstein, W.O. \& Neuhaus P. (2000) Arterial complications after liver transplantation. Transpl Int Vol. 13(No. 5): 372-378.

Soejima, Y., Taketomi, A., Yoshizumi, T., Uchiyama, H., Harada, N., Ijichi, H., Yonemura, Y., Shimada, M. \& Maehara, Y. (2006) Feasibility of left lobe living donor liver transplantation between adults: an 8-year, single-center experience of 107 cases. Am J Transplant Vol. 6(No. 5): 1004-1011. 
Stange, B.J., Glanemann, M., Nuessler, N.C., Settmacher, U., Steinmüller, T. \& Neuhaus P. (2003) Hepatic artery thrombosis after adult liver transplantation. Liver Transpl Vol. 9(No. 6): 612-620.

Suehiro, T., Ninomiya, M., Shiotani, S., Hiroshige, S., Harada, N., Minagawa, R., Soejima, Y., Shimada, M. \& Sugimachi, K. (2002) Hepatic artery reconstruction and biliary stricture formation after living donor adult liver transplantation using the left lobe. Liver Transpl Vol. 8(No. 5): 495-499.

Takatsuki, M., Chiang, Y.C., Lin, T.S., Wang, C.C., Concejero, A., Lin, C.C., Huang, T.L., Cheng, Y.F. \& Chen, C.L. (2006) Anatomical and technical aspects of hepatic artery reconstruction in living donor liver transplantation. Vol. 140(No. 5): 824828.

Taketomi, A., Kayashima, H., Soejima, Y., Yoshizumi, T., Uchiyama, H., Ikegami, T., Yamashita, Y., Harada, N., Shimada, M. \& Maehara, Y. (2009) Donor risk in adultto-adult living donor liver transplantation: impact of left lobe graft. Transplantation Vol. 87(No. 3): 445-450.

Trotter, J.F., Adam, R., Lo, C.M. \& Kenison, J. (2006) Documented deaths of hepatic lobe donors for living donor liver transplantation. Liver Transpl Vol. 12(No. 10): 14851488.

Uchiyama, H., Harada, N., Sanefuji, K., Kayashima, H., Taketomi, A., Soejima, Y., Ikegami, T., Shimada, M. \& Maehara, Y. (2010a) Dual hepatic artery reconstruction in living donor liver transplantation using a left hepatic graft with 2 hepatic arterial stumps. Surgery Vol. 147(No. 6): 878-886.

Uchiyama, H., Hashimoto, K., Hiroshige, S., Harada, N., Soejima, Y., Nishizaki, T., Shimada, M. \& Suehiro, T. (2002) Hepatic artery reconstruction in living-donor liver transplantation: a review of its techniques and complications. Surgery Vol. 131 (1 Suppl): S200-204.

Uchiyama, H., Ikegami, T., Soejima, Y., Ninomiya, M., Kayashima, H., Taketomi, A., Shirabe, K. \& Maehara, Y. (2010b) Use of recipient's left hepatic artery for artery reconstruction in right lobe living donor liver transplantation with duct-to-duct anastomosis. Transplantation Vol. 89(No. 8): 1016-1021.

Uchiyama, H., Shirabe, K., Taketomi, A., Soejima, Y., Ninomiya, M., Kayashima, H., Ikegami, T. \& Maehara, Y. (2010c) Extra-anatomical hepatic artery reconstruction in living donor liver transplantation: can this procedure save hepatic grafts? Liver Transpl Vol. 16(No. 9): 1054-1061.

Uchiyama, H., Soejima, Y., Taketomi, A., Yoshizumi, T., Harada, N., Ijichi, H., Yonemura, Y. \& Maehara, Y. (2007) Hepatic artery aneurysm arising from an interposition vein graft four years after auxiliary partial orthotopic liver transplantation. Transpl Int Vol. 20(No. 2): 197-200.

Yanaga, K., Lebeau, G., Marsh, J.W., Gordon, R.D., Makowka, L., Tzakis, A.G., Todo, S., Stieber, A.C., Iwatsuki, S. \& Starzl, T.E. (1990a) Hepatic artery reconstruction for hepatic artery thrombosis after orthotopic liver transplantation. Arch Surg Vol. 125(No. 5): 628-631.

Yanaga, K., Tzakis, A.G. \& Starzl, T.E. (1990b) Partial dearterialization of the liver allograft. Transpl Int Vol. 3(No. 4): 185-188. 
Wang, C.C., Lin, T.S., Chen, C.L., Concejero, A.M., Iyer, S.G. \& Chiang, Y.C. (2008) Arterial reconstruction in hepatic artery occlusions in adult living donor liver transplantation using gastric vessels. Surgery Vol. 143(No. 5): 686-690.

Wei, W.I., Lam, L.K., Ng, R.W., Liu, C.L., Lo, C.M., Fan, S.T. \& Wong, J. (2004) Microvascular reconstruction of the hepatic artery in live donor liver transplantation: experience across a decade. Arch Surg Vol. 139(No. 3): 304-307. 


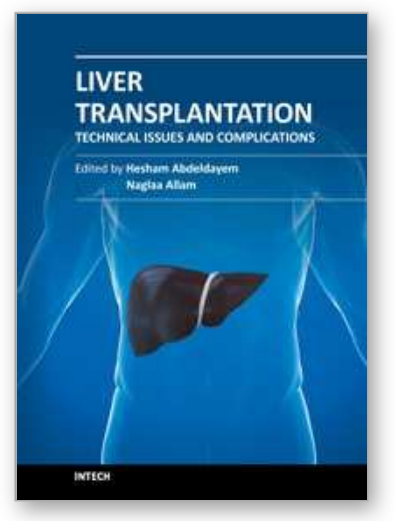

\author{
Liver Transplantation - Technical Issues and Complications \\ Edited by Prof. Hesham Abdeldayem
}

ISBN 978-953-51-0015-7

Hard cover, 454 pages

Publisher InTech

Published online 10, February, 2012

Published in print edition February, 2012

This book covers a wide spectrum of topics including, but not limited to, the technical issues in living and deceased donor liver transplant procedures, cell and experimental liver transplantation, and the complications of liver transplantation. Some of the very important topics, such as the arterial reconstruction in living donor liver transplantation, biliary complications, and the post-transplant-lymphoprolifrative disorders (PTLD), have been covered in more than one chapter.

\title{
How to reference
}

In order to correctly reference this scholarly work, feel free to copy and paste the following:

Hideaki Uchiyama, Ken Shirabe, Akinobu Taketomi, Yuji Soejima, Tomoharu Yoshizumi, Toru Ikegami, Noboru Harada, Hiroto Kayashima and Yoshihiko Maehara (2012). Microvascular Hepatic Artery Reconstruction in Living Donor Liver Transplantation, Liver Transplantation - Technical Issues and Complications, Prof. Hesham Abdeldayem (Ed.), ISBN: 978-953-51-0015-7, InTech, Available from: http://www.intechopen.com/books/livertransplantation-technical-issues-and-complications/microvascular-hepatic-artery-reconstruction-in-living-donorliver-transplantation

\section{INTECH}

open science | open minds

\section{InTech Europe}

University Campus STeP Ri Slavka Krautzeka 83/A 51000 Rijeka, Croatia Phone: +385 (51) 770447 Fax: +385 (51) 686166 www.intechopen.com

\section{InTech China}

Unit 405, Office Block, Hotel Equatorial Shanghai No.65, Yan An Road (West), Shanghai, 200040, China 中国上海市延安西路65号上海国际贵都大饭店办公楼405单元 Phone: +86-21-62489820

Fax: +86-21-62489821 
(C) 2012 The Author(s). Licensee IntechOpen. This is an open access article distributed under the terms of the Creative Commons Attribution 3.0 License, which permits unrestricted use, distribution, and reproduction in any medium, provided the original work is properly cited. 